\title{
COVER ILLUSTRATION
}

\section{Superlatives}

B iologists dream in the superlative. Whales are the largest mammals, cheetahs are the fastest vertebrates, bar-headed geese fly the highest of any bird, and so forth. But you would be hard pressed to think of superlative features when it comes to turtles, or even reptiles. Rest assured there are superlatives in this order. Superlatives among reptiles are still with us.

Marine turtles, in some form, date from at least the Triassic period as early as 220 million years ago. For the next 100 million years, there was a rich diversity of other marine reptiles as well, but most of these were lost by the end of the Cretaceous period, 65 million years ago. Yet, marine turtles endured.

There was a monster sea turtle living during the Cretaceous period. Archelon and its few relatives ruled the sea as a 5 metre, $2500 \mathrm{~kg}$ behemoth turtle, but this animal became extinct shortly after the dinosaurs. But an intriguing and closely related shard of a family from this ancient lineage can still be found in our modern seas, although it is probably heading for extinction too.

Dermochelys coriacea, the leatherback marine turtle (see cover image of Tilly), is the sole member of the family Dermochelyidae, and is closely related to the family Protostegidae, which contained Archelon. The leatherback is almost as grand as Archelon, and deserves the word "grand" as a superlative. It is the largest extant reptile weighing almost $1000 \mathrm{~kg}$, although animals that big probably no longer ply the seas because of human predation. It rivals the great whales and the arctic tern for its panoceanic, pole to pole migrations and is also the fastest growing reptile.

We think of turtles as slow but this marine turtle is a strong and fleet swimmer and can outmanoeuvre a shark and dive to at least 1200 metres. To do this, they have rather extraordinary physiology, especially for a reptile. These turtles maintain a relatively warm muscle temperature, much like the tuna described in a previous issue of $B J O$ (May 2002) by using fatty insulation and a countercurrrent exchange system in their limbs. Their body temperature

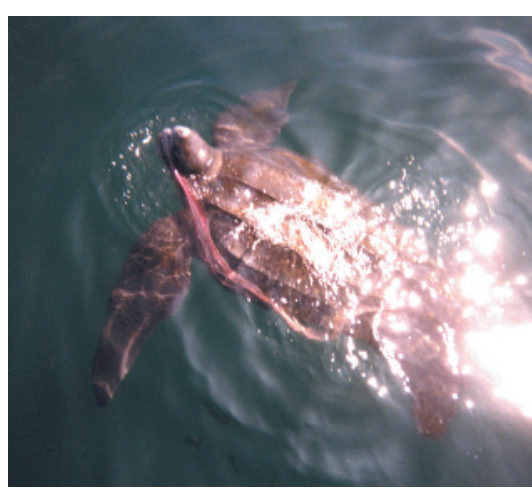

Leatherback turtle with partially eaten lion's mane jellyfish.

can be as much as $18^{\circ} \mathrm{C}$ above the surrounding seawater, providing the necessary metabolism for such long distance odysseys.

Leatherbacks primarily dive in open ocean to feed, in contrast with the other species of marine turtles that tend to feed in more epipelagic or coastal waters. Visual ecology generally determines visual specialisation, and this would appear to be true in leatherbacks. In their retina, these great turtles have relatively wide visual streaks-horizontal concentrations of ganglion cells akin to the infula and concentrated photoreceptors of flamingos ( $B J O$ August 2000). But, the leatherback has another concentration of ganglion cells in the superior temporal portion of the retina called the "area temporalis" (Oliver LJ et al, Mar Fresh Behav Physiol 2000;33:233$48)$. To understand the area temporalis, one needs to understand the natural history of these magnificent animals. Leatherbacks feed on jellyfish and these gelatinous prey may aggregate at any depth. Leatherbacks probably will use this concentrated area of visual cells to spot the aggregation in the water column below them. The optics of the adult eye has not been analysed although that of the hatchling has been. The hatchling is emmetropic at distance with an air interface, but this may change in an adult. Their acuity is not particularly sharp, nor does it need to be. After all, the jellyfish these turtles eat will be large and easily visible. Most marine turtles are diurnal animals, but the leatherback is an exception and shows diurnal and nocturnal activity and feeding behaviour.

Leatherbacks are specialists in that they feed primarily and almost exclusively on cold jellyfish. Jellyfish are diploblasts and have virtually the same concentration of salt as the surrounding seawater. Additionally, when a leatherback eats a jellyfish it will swallow a lot of seawater, and has a throat designed to help it eliminate some of that seawater. Its oesophagus has backward directed oesophageal papillae that retain the jellyfish but allow the oesophagus to expel much of the excess water with a strong muscular contraction. Interestingly, virtually the entire gut can extract oxygen from seawater as well.

But, this still leaves the turtle with a salt problem. The seawater and the jellyfish are a salt load that must be managed. Remarkably, the answer to this problem is the lacrimal gland, which is modified to concentrate and excrete salt. And, here is where the real superlative should be applied to this magnificent creature. The lacrimal glands of the leatherback are nearly twice the size of its brain! These glands are used to concentrate and excrete salt, and must be the largest lacrimal glands for body weight of any creature. This turtle is so efficient at concentrating and excreting salt that a hatchling that has been deprived of fluids to the point of reducing its weight by $10 \%$ will drink seawater to rehydrate! If activated, the lacrimal glands can excrete fluid that is six times the concentration of blood and twice that of seawater (Lutz PL, Musick JA, eds. The biology of sea turtles. Boca Raton: CRC Press, 1996:348-9)

As you can see, the superlatives are still with us, even in reptiles.

I R Schwab,

University of California Davis, 4860 Y Street Suite 2400, Sacramento, CA 95817, USA irschwab@ucdavis.edu

K Fritsches,

Vision, Hearing, and Touch Research Centre, University of Queensland, Brisbane Australia

Photographs courtesy of Nova Scotia Leatherback Turtle Working Group, Halifax, Nova Scotia (www.seaturtle.ca). 